\title{
In-between architecture and landscape, from theory to practice
}

\author{
B. Ott \\ Department of Architecture, \\ State University of New York at Buffalo, USA
}

\begin{abstract}
As both a theoretical and a practical construct, the domain that is neither architecture nor landscape, but of both, is a fertile ground for reflection. The theoretical is addressed by referencing an article by Rosalind Krauss which graphically relates sculpture, architecture and the landscape, including the domains in which they merge. However, the focus here is on the practical: in practice. The last forty years has seen an ideological shift born in the nascent environmental movement of the 1960s. The urge to connect a building to its context, to the landscape, to nature, has become common as we explore new technologies and materials, and mindfully engage siting options in order to produce more sustainable buildings. Presented and elaborated upon are three strategies, with examples, by which to approach this impulse: the metaphysical (by means of the analogy and metaphor), the spatial (as both relational and referential), and the physical, which includes all things material and technological. I conclude with a project in my practice which is driven by the idea that a building can sit in-between architecture and landscape.

Keywords: architecture and landscape, environmental architecture, buildings and nature.
\end{abstract}

\section{Theoretically speaking}

As a theoretical construct, the domain that is neither architecture nor landscape, but of both, is a fertile ground for reflection. From Rosalind Krauss' articles of the mid-1970s to Virgil's dictum that all architecture is an act of violence, we have pondered the encounter of the built with its physical context. Every act of intervention we make into the world is an interruption, an intrusion, in Virgil's 
sense, not an act of beneficence. Small wonder this relationship of opposites is difficult to reconcile, except through a simple dialectic.

To elaborate on a particular work of Krauss: in her article, "Sculpture in the Expanded Field," Krauss pursues a "strategy for reducing anything foreign in either time or space, to what we already know and are" [1] by conjuring a theoretical framework for a set of relations between sculpture, architecture and landscape. She employs an evolving geometric form in which sculpture, architecture and landscape are related, in part by their negatives. In the ultimate version, the inherent complexities in these relationships are filled out with sculpture opposed to site construction, not-architecture to both landscape and architecture, and not-landscape to both architecture and landscape. Her diagram, fig. 1, reveals other relationships which, altogether, wrap the essential dichotomy in a compelling abstract unity.

\section{Practically speaking}

It is always difficult to translate theory into practice, nowhere more so than when trying to bridge the dichotomy between architecture and landscape. As a practical construct, a building, along with the teaspoon, is the epitome of the designed artifact: the antithesis of nature. Every bit of a building's construction is about control, about human ordering systems, systems to which the natural world and its behaviors are totally indifferent. In current practice, the desire to connect an artifact with its opposite is a relatively new obsession, spurred by an ideological shift that was born in the nascent environmental movement of the 1960s. At this point in time, rare are the projects subscribing to the modernist canon and its relative disregard for context and environmentally sensitive orientation and material use. One of the primary tenants of the modern movement was to employ the landscape - or any context for that matter - as background to the artifact of desire. The last thirty-five years has seen a gradual erasing of that canon, replacing it with the themes of this conference.

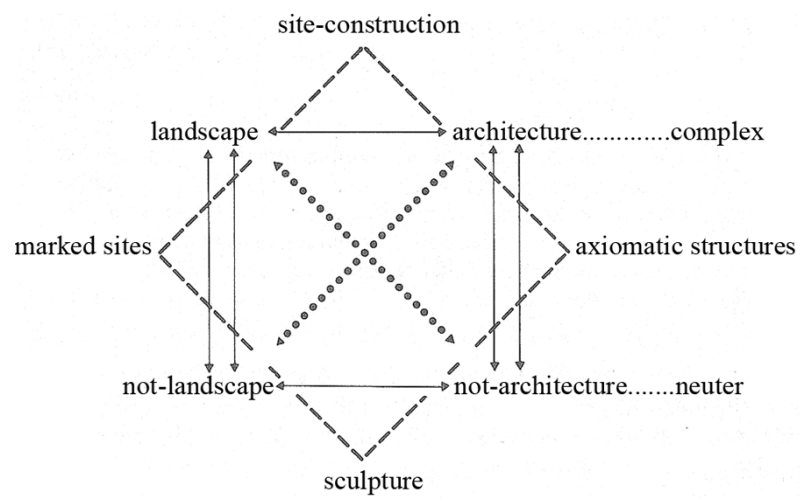

Figure 1: Krauss' diagram. 
The urge to connect a building, in some way, to the ecology in which it exists has met with all manner of strategies, from the metaphysical to the spatial to the physical. Following is a brief elaboration of these strategies, concluding with a project in my practice which engages two of the strategies.

\subsection{The metaphysical}

In the metaphysical realm, the analogue and the metaphor have been in use since the rising sun was equated with a new beginning and a mountain top construed as access to the celestial theater. Analogically, the recent project by Foreign Office Architects for the International Passenger Terminal located on the river's edge in Yokohama, Japan is analogous to a wave; while is not a wave, it is like a wave, made of ten low-slung flowing ramps which at once enfold the outside and weave over and under the main passenger ship terminal, fig. 2.

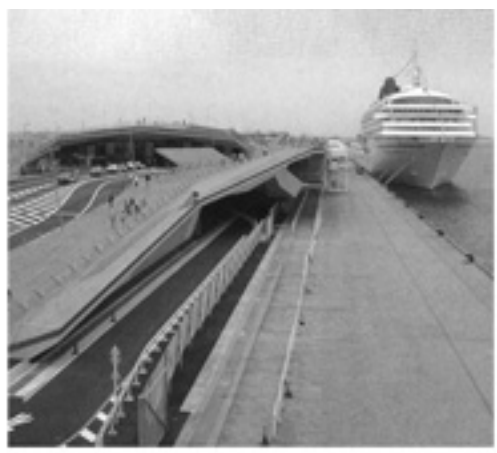

Figure 2: Yokohama Terminal.

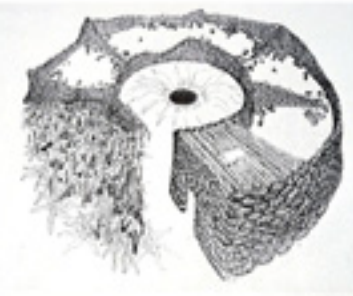

Figure 3: Growth House.

The building as metaphor - in which something actually acts as something else - to me is both more interesting, and more difficult to accomplish, than the increasingly literal and plastic analogous forms used to represent aspects of the non-built environment. Charles Simmonds' Growth House, a 1975 project installed at Art Park in upstate New York, is a kitchen garden. Circular walls constructed out of carefully sequenced burlap bags of seeds begin to sprout in the rainy spring. First the crocuses emerge, then the spinach, herbs, peppers, and tomatoes; on to fruit, squashes and so forth as the growing season ends and the walls have literally been eaten by visitors to the park [2], fig. 3 .

Also metaphoric is my selected entry to the ChiChi Earthquake Memorial competition of 2003. The site is a park in the midst of the region just south of Taipei, Taiwan, hardest hit by the earthquake of 1998. My team proposed the construction of a fault crack dug into the earth as a memorial path through the park. Its interior walls, left rough in excavation, are reinforced with foundations, and anchored into the earthen walls with a steel space frame; an open metal mesh 
is all that separates the visitor from the perpetrator; the design is a formal and material reenactment of the event itself, figs. 4 .

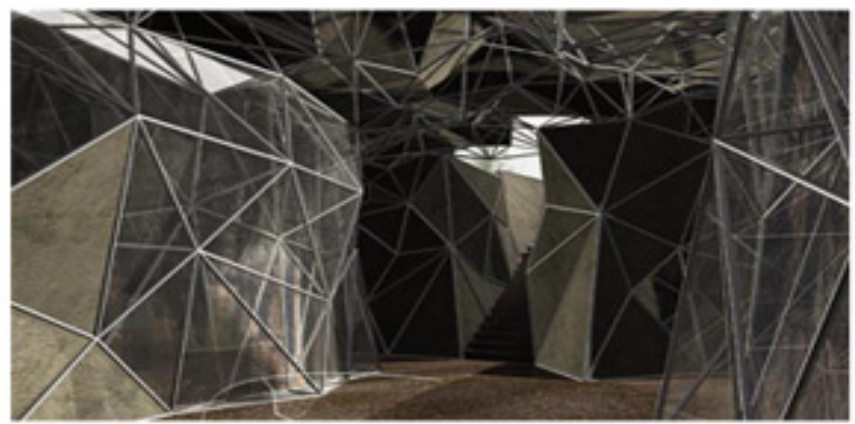

Figure 4: ChiChi Earthquake Memorial.

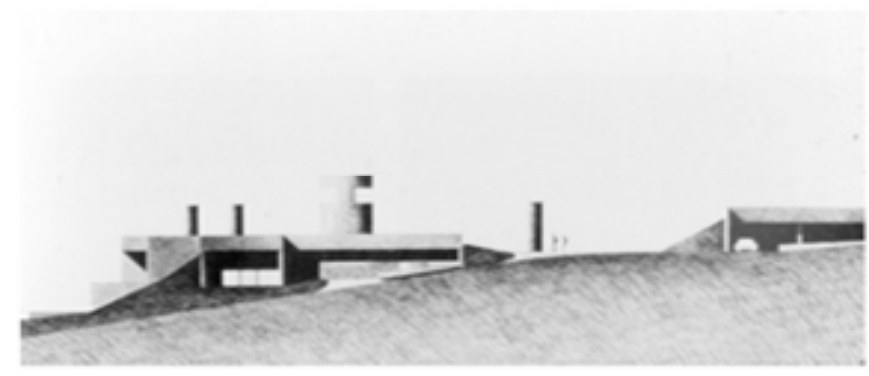

Figure 5: Choate House.

\subsection{The spatial: relations and references}

Of the strategies which attempt to connect buildings to aspects of nature, the relational and referential are primarily context driven and spatial.

Buildings embedded into grade, stepping down a hillside, or perched on a rock outcrop are formally defined by their direct, formal relation to the lay of the land. By example is Roland Choate's mid-1970s Monticito house located in the dry coastal foothills of Southern California, fig. 5. This project replaces a house destroyed in a wildfire. In its stead, Choate designed a structure all but impervious to fire: it is submerged into the hillside, with exposed and carefully detailed concrete retaining walls and floor; the uphill fragments of the building are minimal and the furnishings present the barest of fire loads. Down the hillside, directly in front of the glass enclosing wall, a swimming pool is plumbed to be a fire fighting reservoir. The building is a fire-deflecting instrument; the form and materiality of the house is generated by the form and materiality of the fire. There is a direct relationship between house and fire.

Similar to buildings that relate directly to the land are those which refer to the forms and forces of nature; buildings which define themselves not in terms of 
these forms or forces, but as a reference to them. In early eighteenth century India, Maharaja Sawai Jai Singh, a student of astronomy, concluded that at that time, astronomy was limited to analysis through mathematical calculations and couldn't adequately observe the cosmos. After consulting authorities on astronomy, especially those using direct observation, Singh set out to construct two masonry observatories, one in the heart of Delhi in 1724 and the other in Jaipur in 1728, fig. 6. These large scale architectural versions of astronomical instruments are a particularly literal reference to the celestial theater. With intent to improve the accuracy of celestial observations, these poetic constructions measure the rotation of the sun; its movement is magnified as its shadow sweeps across articulated hemispherical cavities. In addition, the positions of the stars are seen in precise alignment from points within its deep bowl [3].

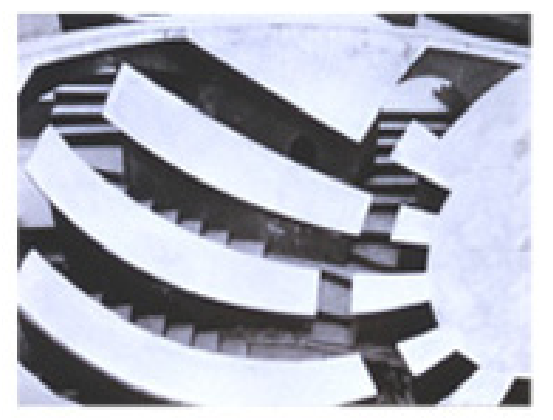

Figure 6: Solar Observatory at Jaipur.

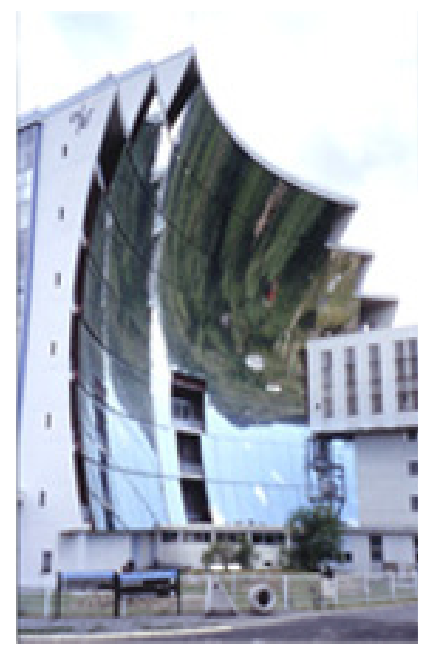

Figure 7: $\quad$ Solar Ovens at Odello. 
The Delhi and Jaipur observatories are indexes; they point to, refer to, celestial dynamics. In a similar vein is another structure to mention which not only refers to the sun, but uses it (an early form of a passive solar design). One of a few such structures located in the French Pyrenees is the solar oven near Odelló, fig. 7. This elegant and ingenious structure, by means of a mindfully placed field of reflecting mirrors, reflects and focuses the sun's energy ... in order to bake bread!

\subsection{The physical}

The strategy I have labeled physical includes both the material and technological, and usually refers to sustainability in one way or another. By clever material and formal choices or by simply employing the laws of physics, we can heat, cool, moderate temperatures; create a breeze or buffer the wind. We can use the dispersal of cached water as a resource or an aesthetic; likewise, the sod roof, the heat sink, and the overhang. Examples abound as this strategy is gradually enfolded into the common sense that underlies the practical act of design.

One such project rises to the surface: the Academy Mount Cenis built on a former mine site at the center of the town of Sodingen in Germany's Rhur Valley, figs. 8, 9. The concept for this project is extraordinary in its simplicity. A glass shell, outfitted with louvers, p.v. cells patterned for optimal heat capture and shading, a loose stone floor as heat sink, and a system of water catchment and reuse, create a year-round interior environment similar to Marseilles, on the French Riviera, some $10^{\circ}$ latitude south of the mine site. Inside, the educational and public offices are housed in bar buildings which face each other to create a warm weather street, complete with an 'outdoor' café. This building produces much more energy than it consumes; it distributes the remainder to the town [4].
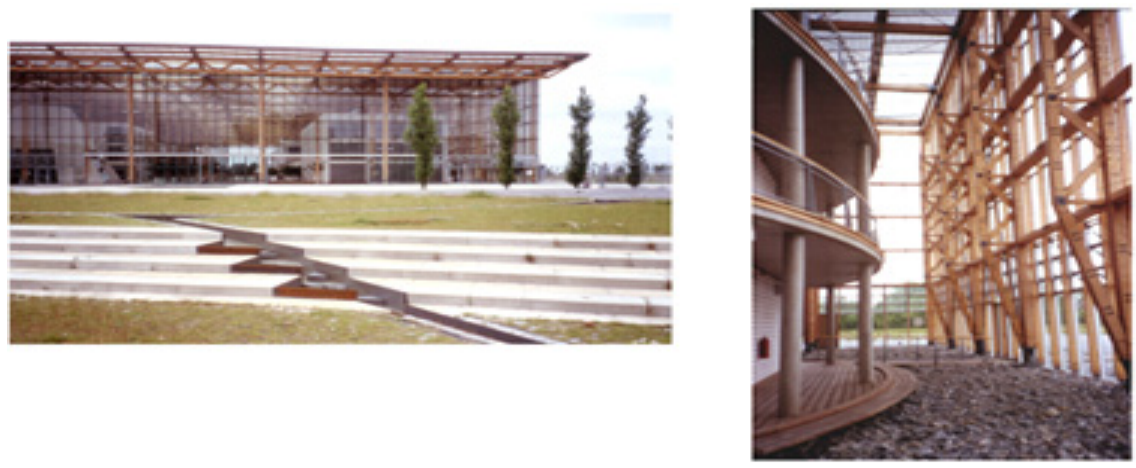

Figures 8, 9: $\quad$ Mt. Cenis Academy.

\subsection{The project}

I would like to elaborate on these strategies to link architecture with landscape with a project I am working on for a small ceramic studio, currently under construction in Ithaca, New York. The design of this building focused on two of 
these strategic realms: the relational and the physical. The primary design strategy was to slide the building into the land in such a way as to render the building an element in the landscape from the entry side and as an artifact from the other, making every possible decision in relation to the site's physical location and orientation, its specific topography, aspects of the celestial theater, the available vista, and the color of the land.

Design priorities for the studio were to orient to a west-facing view over the lake and to provide year-round passive heat control with no moving air to disperse ceramic dust. These conditions resist each other: a western view, over a lake, requires both solar and glare control. By rooting the studio 4' into grade with a bracketing set of 13 " concrete block retaining and cavity walls, we accomplish two things: the future patio is framed by what nominally appears to be a garden wall, and below grade construction serves as a natural insulator and heat sink. The west view wall is spanned in low-e glass and protected with exterior solar shades. With a relatively low-slung ceiling and radiant floor heat for the winter, and ventilation through operable windows and doors instead of ceiling fans in the summer, moving air is kept to a minimum.

As well, the interior was to be hosed down on occasion. To ensure hoseability, there are no finishes inside this building other than sheets of exterior grade plywood on frame walls. The sloped-to-drain, coil-heated slab has a brushed finish for traction and is colored $40 \%$ grey for heat absorption, the interior face of the block walls are polished, and the exposed wood roof decking oiled.

To reuse water runoff, roof gutters sloped to scuppers at three locations distribute water into the landscape. In terms of solar energy recapturing, future solar panels or cells would be outfitted onto the south facing roof. The roof actually bears $7^{\circ}$ to the west of south; with a roof slope of $21^{\circ}$, at $42^{\circ} \mathrm{N}$. Latitude, the setup is almost optimal in regards to the sun and its potential.

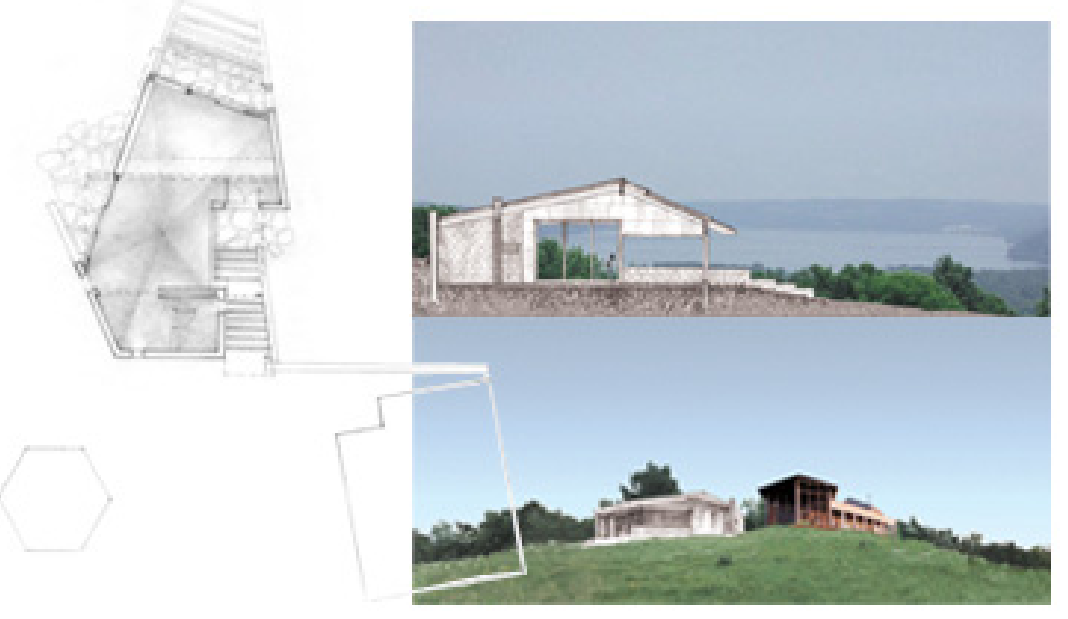

Figures 10, 11, 12: Ceramic studio. 


\section{Conclusion}

By paying attention to the vast sets of possibilities which allow the human arts of design and building to garner significance from the natural world, theory and practice take on new meaning. Ecologically engaging architecture is practical, can be poetic, and provides endless opportunities to dance around in Krauss' diagram.

\section{References}

[1] Krauss, R., Sculpture in the expanded field. The Anti-Aesthetic: Essays on Postmodern Culture, ed. H. Foster, Bay Press: Port Townsend, WA, pp 31-42, 1985.

[2] Lippard, L., Overlay: Contemporary Art and the Art of Prehistory, Pantheon Books: New York, 1983.

[3] Perlus, B., Jantar Mantar. Parabola, XV, 1, pp. 65-73, 1990.

[4] Stadt Herne, Entwicklungsgesellschaft Mont-Cenis, Druckerei Frisch GmbH: Herne, Germany, 1998. 